\title{
Peritoneal Surface Disease
}

National Cancer Institute

\section{Source}

National Cancer Institute. Peritoneal Surface Disease. NCI Thesaurus. Code C159588.

A condition characterized by widespread neoplastic disease of the peritoneum. Most

often, the origin of the neoplasm is outside the peritoneum, but in rare cases the tumor may be primary. 